\title{
Two Cases of Pulmonary Alveolar Microlithiasis in a Family
}

\author{
MANSOURI FARIBA ${ }^{1}$, KAVIANPOUR MOHAMAD ALI ${ }^{1}$
}

\begin{abstract}
Pulmonary alveolar microlithiasis is a disease of unknown etiology. The disorder affects people at every age beginning from the early childhood. It usually occurs in a sporadic form, but an autosomal recessive form has been described, especially in patients from the Mediterranean countries.

Our cases were in one family. A 44 years old man and his younger(35 years old) sister. Both of them complaint of dyspnea, bluish discolouration of face and extremities (acrocyanosis), clubbing, and coughing

We evaluate both of them. These are findings in the male patient, and his sister had very similar findings. CXR and CT scan findings imply that we had 2 case of pulmonary alveolar microlithiasis (PAM).

Key words: Pulmonary alveolar microlithiasis, Autosomal Recessive
\end{abstract}

\section{Introduction}

Pulmonary alveolar microlithiasis is a disease of unknown etiology. The disorder affects people at every age beginning from the early childhood. Familial occurrence is often found with family history of the disease being present in up to $50 \%$ of the reported cases. ${ }^{1}$ There are few cases which all were between 30 to 60 years old. ${ }^{2}$ It usually occurs in a sporadic form, but an autosomal recessive form has been described, especially in patients from the Mediterranean countriese. Lack of association between radiologic and clinical findings is more striking in this disease than in any other condition. It is a silent but progressive disease, and in the almost of cases it has been detected by a chest $\mathrm{x}$ ray with other purposes. ${ }^{3}$ In this disease calcium deposits in alveolar septi and cavity. There is no report of serum electrolyte abnormalities.

\section{Case Report}

The patient is a 44 years old man with a history of cough and dyspnea from 3 years ago has admitted because of worsening of dyspnea and coughing. He has nonproductive coughs. He has dyspnea at rest and in exertion he has orthopnea.He has history of cyanosis in tip of hand fingers. He has chest pain which worsens by respirative movements. He does not complaints of fever,shake,night sweating and weight loss.I $\mathrm{n}$ his past medical history , He has history of chronic sinusitis. In drug history there are drugs such as salbutamul, theophyline,etc.In habitual history he does not smoke and there is no history of alcohol or opium, but he hasnot history of exposure to chemical substances. In the physical

1. Respiratory department, Emam Reza hospital, Kermanshah university of Medical Science, Kermanshah, Iran

Correspondence : Dr. Fariba Mansouri, Pulmonologist, Respiratory department, Emam Reza hospital, Kermanshah university of Medical Science, Kermanshah, Iran. Phone: +98 831 4276309, Fax:+98 4276356, e-mail: faribaman2003@yahoo.com examinations positive signs are as follows: Fine inspiratory and expiratory crackles in both sides of lung and the signs of cor-pulmonale.He has digital clubbing , acrocyanosis and Edema grade 2 in lower extremities.

Pulmonary function studies shows a restrictive defect with decreased vital and total lung capacity, normal residual volume/total lung capacity ratio and decreased diffusing capacity. values of chemical analysis of blood are within normal limits, but the calcium level was lower than normal limit with normal level of phosphor, PTH and vit D (documented in tow separate checkup)

He has documented the presence of PAM via chest X-ray and confirmed it by computerized tomography. Transthoracic echocardiographic examination has revealed the presence of severe pulmonary hypertension, and otherwise normal echocardiographic findings.

In his family there is similar complaints in his younger sister (dyspnea, cyanosis, reduced respiratory volumes, CXR and CT scan findings,also cor pulmonale). She has normal calcium, phosphor and PTH levels, and in further evaluation by chest X-ray and computerized tomography she was another case of PAM.

On the time of admition vital signs were as follows:

Blood pressure:110/70, PR:80, RR:24, T:37'c

In the physical examinations positive signs are as follows:

Fine expiratory crackles in both sides. Clubing and acrocyanosis. Edema grade 2 in lower extremities. Dopler sonography of right leg is normal.In Echocardiography lvef is $50 \%$ and there is shift of interventricular septum to left ventricle due to high right ventricle pressure,moderate to severe right atrium an right ventricle enlargement, severe right ventricle systemic dysfunction,mild tricuspid valve regurgitation,pulmonary arterial pressure is $51 \mathrm{~mm}$,minimal 

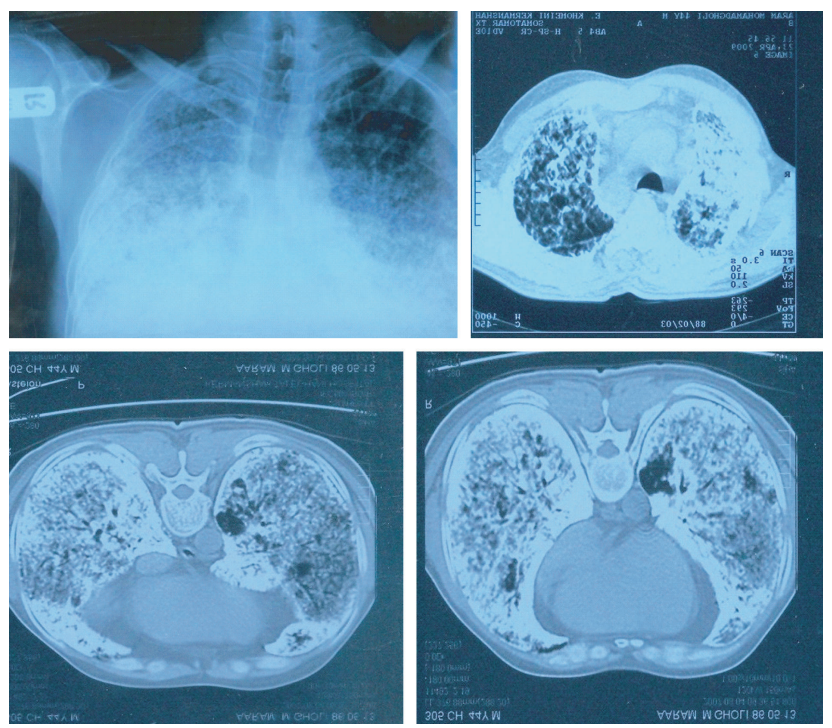

Fig.-1 : Showing radiological features in patient

pericardial effusion.In Abdominal and Pelvic sonography liver is congested to some how.Billiary ducts have normal size and pattern.wall of gall bladder is thickened and is edemato.There is some sludge and 1 or 2 small lithiasis in gall bladder.Pancreas and spleen are normal.Kidneys are normal.there is no lymphadenopathy.

\section{Lab Studies}

$\mathrm{WBC}=82000$ with seg of $66.7 \%, \mathrm{RBC}=6950000, \mathrm{Mcv}=72.7$, $\mathrm{Hb}=15.5$, Hct $=50.5 \%$, Plt $=167000$,

$\mathrm{Pt}=17.6, \mathrm{Ptt}=30, \mathrm{Inr}=1.8$,

$\mathrm{Ca}=6.1, \mathrm{P}=4, \mathrm{Na}=138, \mathrm{~K}=4.1$,

$\mathrm{Ast}=43, \mathrm{Alt}=42, \mathrm{Alkp}=178$,

Bili total $=1$, Bili direct $=0.3$,

$\mathrm{Bs}=96$,

$\mathrm{Urea}=49, \mathrm{Cr}=1.2$, Urin $24 \mathrm{~h}$ volume $=700 \mathrm{cc}, \mathrm{Cr} / 24 \mathrm{~h}=1652$, $\operatorname{Pr} / 24 \mathrm{~h}=357$, Urin Ca level $=11.2$,

Serology:

RA factor is negative, ANA factor is negative, CRP is 2+, $\mathrm{ESR}=4$

AFB is negative, BK culture is negative,

T4 $=7.5$ normal, $\mathrm{T} 3=0.73$ normal, $\mathrm{TSH}=2.8$ normal, $\mathrm{PTH}=$ normal

$\mathrm{ABG}: \mathrm{Ph}=7.37, \mathrm{Pco} 2=33, \mathrm{Po} 2=47.6, \mathrm{So} 2=80 \%, \mathrm{Hco} 3=19.5$

\section{Discussion}

The cause of the disease is quite unknown. It may occur in any age between infancy and 80 years but the majority are diagnosed between the age of 30 - 60 years. Some investigators have documented a predilection for men or women, however most have found no sex predominance. ( It occurs equally in men and women). ${ }^{2,3,4}$ The disease exhibits a strong familial tendency. A familial occurrence has been noted in approximately half the reported cases. $3,4,5$ The age of our 2 cases are between 4 nd to 5 th decade and one is female and one is male.

Most patients are asymptomatic when the disease is discovered by routine radiography. When the patient is symptomatic, most common symptom is dyspnoea on exertion. Cough develops in some patients although it is typically nonproductive. Chest pain is uncommon. ${ }^{6}$ Haemoptysis occasionally occurs. ${ }^{7}$ There are often no physical signs in the chest even when the radiography is grossly abnormal, later there may be inspiratory crepitation and ultimately the signs of cor-pulmonale, values of chemical analysis of blood are invariably within normal limits. ${ }^{8}$ Biopsy shows calcified spherules filling alveolar spaces. The spherules have a concentric lamelleted appearance suggesting that they grow by the addition of successive layers. The spherules contain both calcium and phosphorus. ${ }^{6,7,8}$ Our patients had symptoms like non productive cough, dyspnoea on exertion, cough with scanty expectoration. In our patients there were scattered crepitations at lung bases. The mechanism which may induce microliths to form is unknown. The most accepted hypothesis suggested an inherited metabolic abnormality limited to the alveolar surface involving the enzyme carbonic anhydrase, which promotes alkalinity in the alveoli with consequent precipitation of calcium and the development of calcospherites. $^{8,9}$

The disease, in many patients, was misdiagnosed as miliary tuberculosis, sarcoidosis, ${ }^{8}$ silicosis, hemosiderosis, and pneumonitis. ${ }^{8,9,10,11}$ In general, it appears that PAM has a protracted clinical course. The patients of pulmonary alveolar microlithiasis produce a characteristic radiographic appearance. The lung fields are diffusely occupied by discrete high density opacities resembling grains of sands and when profuse, produce 'white out' of the lung. ${ }^{12,13}$ Pulmonary function studies are initially normal. In about $30 \%$ of the patients, a restrictive defect evolves.

The most common findings are decreased vital and total lung capacity, normal residual volume/total lung capacity ratio and decreased diffusing capacity. ${ }^{13}$ The over all density is greater over the lower than the upper zone. The opacity may be so numerous as to appear confluent showing the lungs as almost uniformly white often with total obliteration of the mediastinal and diaphragmatic contours and pulmonary vascular marking becoming indistinct. ${ }^{7}$ Currently, the only effective therapy is lung transplantation especially when surgery is performed before reaching advanced stages of the disease. It has been reported that PAM cases followed after transplantation did not show evidence of recurrence. ${ }^{14}$

\section{Conflict of Interest : None}




\section{References}

1. Alia S. Al-Alawi, MBBCH, FACP. Familial occurrence of pulmonary alveolar microlithiasis in 3 siblings, Saudi Med J 2006; Vol. 27 (2): 238-240

2. Fraser \& Pare's. Diagnosis of diseases of the chest. 4th Edn. Vol. IV. 1999; 2719-2722.

3. Crofton \& Dugla's. Respiratory diseases 5th edn, Vol.II, $2000 ; 1339-40$.

4. Ucan E.S, Keyf AI, Aydilex R, et al: Pulmonary Alveolar microlithiasis - Review of Turkish reports. Thorax. 1993; 48: 171.

5. Sosman MC, Dodd GD, Jones WD et al. The familial occurance of pulmonary alveolar microlithiasis. Am. J. Roentgenol 1957; 77: 947.

6. Thind G.S, Bhatia JI: Pulmonary Alveolar microlithiasis. Brit J. Dis. Chest. 1978; 72: 151.

7. Fishmans Pulmonary disease \& disorders. 3rd edn, Vol I, 1998; 1155.

8. Grainger \& Allisons, Diagnostic Radiology 3rd edn, Vol I, 1997; 415.
9. Mariotta S, Ricci A, Papale M, De Clementi F, Sposato B, Guidi L, et al. Pulmonary alveolar microlithiasis: Report on 576 cases published in the literature. Sarcoidosis Vasc Diffuse Lung Dis 2004; 21: 173-181.

10. Castellana G, Lamorgese V. Pulmonary alveolar microlithiasis: World cases and review of the literature. Respiration 2003; 70: 549-555.

11. Mariotta S, Guidi L, Papale M, Ricci A, Bisetti A. Pulmonary alveolar microlithiasis: Review of Italian reports. Eur J Epidemiol 1997; 13: 587-590.

12. Stamatis G, Zerkowski HR, Doetsch N, et al. Sequential bilateral lung transplantation for pulmonary alveolar microlithiasis. Ann Thorac Surg 1993; 56: 972-5.

13. Edelman J, Bavaria J, Kaiser LR, et al. Bilateral sequential lung transplantation for pulmonary alveolar microlithiasis. Chest 1997;112:1140-4.

14. Gönenç Ortaköylü, Alev Ketenci, Bahadýr Aype, Çaðlar Emel, Ürer Nur, Pulmonary Alveolar Microlithiasis, Turkish Respiratory Journal 2006; 7(1): 34-37

15. SS PATRO, CR KAR, Pulmonary Alveolar Microlithiasis, Ind J Radiol Imag 2006 16:4:879-881 